\title{
Correction
}

\section{Correction: Weaning from mechanical ventilation}

Inmaculada Alía and Andrés Esteban

Hospital Universitario de Getafe, Madrid, Spain

Corresponding author: Inmaculada Alía

Published: 21 July 2006

This article is online at http://ccforum.com/content/10/4/414

Critical Care 2006, 10:414 (doi:10.1186/cc4996)

(c) 2006 BioMed Central Ltd

It has been brought to our attention that there was a typographical error in our review article [1] published in February 2000.

The last sentence of the abstract should read:

"Two randomized studies found that, in difficult-to-wean patients, synchronized intermittent mandatory ventilation (SIMV) is the most ineffective method of weaning."

\section{Reference}

1. Alía I \& Esteban A: Weaning from mechanical ventilation. Critical Care 2000, 4:72-80. 